\title{
Ubenimex Suppresses the Ability of Migration and Invasion in Gastric Cancer Cells by Alleviating the Activity of the CDI3/NABI/MAPK Pathway
}

\author{
Xuehui Liu' \\ Qie Guo ${ }^{2}$ \\ Fanjing Jing ${ }^{2}$ \\ ChangKai Zhou ${ }^{2}$ \\ Ting Xiu' \\ YunYan Shi ${ }^{1}$ \\ FanBo Jing ${ }^{1,2}$
}

'Department of Pharmacology, Qingdao University School of Pharmacy, Qingdao, 26607I, Shandong, People's Republic of China; ${ }^{2}$ Department of Clinical Pharmacy, The Affiliated Hospital of Qingdao University, Qingdao, 266003, Shandong, People's Republic of China
Correspondence: FanBo Jing

Qingdao University, Qingdao, 26607I, Shandong, People's Republic of China Email Jingbf 178@sina.com
Background: Gastric cancer (GC) is one of the most common malignant tumors in China. Most GC patients are diagnosed at an advanced stage, for that the prognosis is dismal and metastasis is common. Although there have been increasing numbers of studies indicating that Ubenimex can suppress metastasis in GC, the underlying mechanism is still unknown. Methods: Herein, the inhibitory effect of Ubenimex on GC metastasis, in which the underlining mechanism was determined using Gene chip analysis, high content screening (HCS), transwell assays, wound healing assays and Western blot assays.

Results: The results obtained from wound healing assays and transwell assays indicated that Ubenimex, an inhibitor of CD13, suppressed the migration and invasion of MKN-28, MGC803, BGC-823 and SGC-790 cells, by downregulating CD13 expression. In addition, the findings acquired from Gene chip analysis and HCS demonstrated that NGFI-A-binding protein 1 (NAB1) was a putative target downstream of CD13. Furthermore, the results obtained from Western blot assays showed that Ubenimex not only inhibits NAB1 expression by targeting CD13, but also inhibits GC metastasis by mitigating the activity of the MAPK signaling pathway. These findings indicated a possible mechanism via the CD13/NAB1/ MAPK pathway of which activity was restrained.

Conclusion: Ubenimex exert the inhibitory effect on GC metastasis by targeting CD13, in which NAB1 expression and the activation of MAPK signaling pathway were both suppressed. This study identified a promising target for the inhibition of GC metastasis.

Keywords: gastric cancer, CD13, Ubenimex, NAB1, MAPK

\section{Introduction}

Gastric cancer (GC) is one of the most common gastrointestinal tumors. ${ }^{1}$ The International Agency for Research on Cancer reported approximately 19.3 million new cancer cases worldwide in 2020 and approximately 10 million deaths. In China, the incidence of GC ranks fourth in malignant tumors, whereas the mortality of GC ranks second. The incidence of GC in China accounts for nearly half of that worldwide, seriously threatening the lives and health of people. ${ }^{2}$ The onset of GC is insidious, and lesions of early disease are limited to the mucosa and submucosa. ${ }^{3}$ Thus, most GC patients are diagnosed at an advanced stage, of which the 5-year survival rate after surgery is less than $30 \%{ }^{4}$ Like many malignancies, GC is prone to metastasis to other organs, such as the liver and lung. ${ }^{5}$ To reduce the mortality rate of GC, new methods for an early diagnosis and new targeting therapy for prevention of metastases are required. 
CD13, also called aminopeptidase N (APN), belongs to the type II membrane metalloproteinase family and is expressed on various tumor cells. CD13 utilizes proteolytic enzymes to promote the vascularization, proliferation, infiltration and metastasis of tumor cells. ${ }^{6}$ No detailed study exists on the direct antitumor effect of Ubenimex, but emerge evidence have indicated combined application with chemotherapy drugs. In particular, Ubenimex produces synergistic effects with 5-fluorouracil and improves the chemotherapeutic effect of 5-fluorouracil towards liver cancer, kidney cancer, breast cancer and other tumors. ${ }^{7}$ Moreover, Ubenimex promotes chemotherapy-induced apoptosis and inhibits the expression of ATP-dependent transporter protein $(\mathrm{ABC})$ transporters, thus reversing multidrug resistance in hepatocellular carcinoma (HCC) cells by targeting CD13. However, as the only CD13 inhibitor currently on the market, Ubenimex is used only as an adjuvant modality combined with chemotherapy as an immunomodulatory therapy. ${ }^{8}$ There is no report on the association between CD13 expression and GC metastasis, much less for the inhibitory of GC metastasis mediated by Ubenimex.

NGFI-A-binding protein 1 (NAB1) belongs a member of the NGFI-A/Egr-binding protein family, ${ }^{9}$ which act as corepressors to interact with Egr2 and are required to properly coordinate myelin formation. ${ }^{10,11}$ The convincing evidence have indicated that NAB1 interacts with HIC-1 allowing normal Wnt secretion as an adaptor for multiple proteins to interact with $\mathrm{F}$-actin to regulate different processes in the nervous system. ${ }^{12}$ NAB1 is also a transcriptional corepressor, and it has been previously identified as a glucocorticoid-responsive gene in hamster smooth muscle cells, and may also be a corepressor that influences inflammatory reactions. ${ }^{13}$ However, few reports have investigated NAB1 in tumors, and no study shown that NAB1 participates in inhibiting GC metastasis.

Mitogen-activated protein kinases (MAPKs) are widely activated in many cell types, which play a pivotal role in promoting tumor growth and metastasis. As reportedly, IDO1 and COL12A1 synergistically promote GC metastasis by forming a positive feedback loop via the MAPK pathway and CXCR7 which was regarded as a chemokine receptor for SDF-1. ${ }^{14}$ Extracellular signal-regulated kinase (ERK) is a core kinase of the MAPK family that regulates the proliferation, apoptosis, differentiation and progression of diverse human cancer cells. Additionally, inactivation of MAPK/ERK pathway diminishes SMARCE1-induced GC cell growth and mobility. ${ }^{15}$ It is recognized that the MAPK signaling pathway plays a role in regulating tumor proliferation, invasion and metastasis. ${ }^{16,17}$ However, few studies have shown the relationship between NAB1 and MAPK in GC cells.

Herein, we demonstrated that Ubenimex inhibits GC metastasis by downregulating the expression of CD13. Furthermore, we performed high content screening (HCS) and found that $\mathrm{NAB} 1$ is a putative target of $\mathrm{CD} 13$ by which Ubenimex suppresses GC. Additionally, Ubenimex may inhibit GC metastasis through the CD13/NAB1/MAPK pathway. Collectively, these results showed that Ubenimex is a promising agent that may inhibit GC metastasis.

\section{Methods}

\section{Reagents and Antibodies}

Ubenimex (purity, $\geq 99.9 \%$ ) was purchased from Shenzhen Main Luck Pharmaceuticals Inc. (Shenzhen, China), dissolved in DMSO and then diluted with sterilized Dulbecco's modified Eagle's medium (DMEM). The final concentration of DMSO in the cultures was $<0.1 \%$. Rabbit monoclonal antibodies against ANPEP (CD13; Abcam Biotechnology, Cambridge, USA; cat. no. ab108382; 1:3000), NAB1 (Abcam; cat. no. ab150389; 1:3000), p-MAPK (Abcam; cat. no. ab151279; 1:250), E-cadherin (Elabscience Biotechnology Co., Ltd, Wuhan, China; cat. no. E-AB-53267; 1:1000), N -cadherin (Elabscience; cat. no.E-AB-70061;1:1000), Vimentin (Elabscience; cat.no. E-AB-18212;1:2000) and $\beta$-actin (Proteintech, Rosemont, IL, USA; cat.no.20536-1-AP; 1:3000) were used in this study. All secondary antibodies (cat.no.SA00001-2; 1:3000) were purchased from Proteintech Biosciences.

\section{Cell Culture}

Human gastric cell lines (MKN-28, MGC-803, BGC-823 and SGC-7901) were purchased from the Cell Bank of the Chinese Academy of Sciences (Shanghai, China) and cultured in DMEM (Gibco, Carlsbad, CA, USA) supplemented with $10 \%$ fetal bovine serum (Gibco), $100 \mathrm{U} / \mathrm{mL}$ of penicillin and $100 \mu \mathrm{g} / \mathrm{mL}$ of streptomycin (North China Pharmaceutical Co., Inc., Shijiazhuang, China) in a humidified incubator with $5 \% \mathrm{CO}_{2}$ at $37{ }^{\circ} \mathrm{C}$.

\section{Plasmid Construction and Gene Amplification}

Enhanced green fluorescent protein (EGFP)-labeled ANPEP (CD13; GenBank number NM_001150), NAB1 (GenBank number NM_001321313) overexpression plasmids and negative control plasmids (empty vector control plasmid; CMV-MCS-3FLAG-IRES-EGFP-SV40-Neomycin) were 
used in this study. We searched for the coding sequence of human NAB1 in GenBank and designed PCR primers. The following primer pairs were designed based on the ANPEP and NAB1 mRNA sequences: ANPEP-p1, 5'-TACCGG ACTCAGATCTCGAGCGCCACCATGGCCAAGGGCTTCTATATTTCCAAG-3'; ANPEP-p2， 5'-TCCTTGTAGTCC ATGGATCCTTTGCTGTTTTCTGTGAACCACTGGAGCAC-3'; NAB1-p1， 5'-TACCGGACTCAGATCTCGAGCG CCACCATGGCTGCGGCCTTACCCAG-3'; and NAB1-p2, 5'-TCCTTGTAGTCCATGGATCCTCTTGAATCTTCAG GCTCTG-3'. The PCR identification primer sequences were as follows: ANPEP-p3, 5'- CAGTACATGCCCTGG GAGGC-3'; ANPEP-p4, 5'- AACGCACACCGGCCTTA TTC-3'; NAB1-p3， 5'-CTCTGTGGCTGAGTGTGTGG-3'; and NAB1-p4, 5'-AACGCACACCGGCCTTATTC-3'. The PCR mixture contained $2 \mu \mathrm{L}$ of cDNA template, $1 \mu \mathrm{L}$ of primer $(10 \mu \mathrm{mol} / \mathrm{L}), 10 \mu \mathrm{L}$ of PCR mix and $\mathrm{dH}_{2} \mathrm{O}$ to a total volume of $20 \mu \mathrm{L}$. The PCR program was as follows: $94{ }^{\circ} \mathrm{C}$ for $5 \mathrm{~min}$; 40 cycles of $94^{\circ} \mathrm{C}$ for $30 \mathrm{~s}, 58^{\circ} \mathrm{C}$ for $30 \mathrm{~s}$ and $72^{\circ} \mathrm{C}$ for $5 \mathrm{~min}$; and a final extension at $72{ }^{\circ} \mathrm{C}$ for $5 \mathrm{~min}$. The final PCR products were separated by electrophoresis using $1 \%$ polyacrylamide gels, and the target fragment was purified and recovered using an agarose gel extraction kit (Watson Biomedical Inc., Shanghai, China).

\section{Cell Transfection}

ANPEP (CD13) and NAB1 overexpression plasmids were used for cell transfections. MKN-28, MGC-803, BGC-823 and SGC-7901 cells were seeded into 6-well cell culture plates and cultured to $80 \%$ confluence. Lipofectamine 3000 reagent (Thermo Fisher Scientific, Inc., USA) was then added, and cells were transfected with plasmids for 24 hours at $37^{\circ} \mathrm{C}$. The procedures were performed according to the manufacturer's instructions.

\section{Gene Chip Analysis and HCS of Cell Function}

The Affymetrix Clariom ${ }^{\mathrm{TM}} \mathrm{S}$ gene chip was used to determine the gene expression spectrum of MKN-28 cells before and after Ubenimex treatment and assess changes in gene expression. In this study, the migration rate of MKN-28 cells was
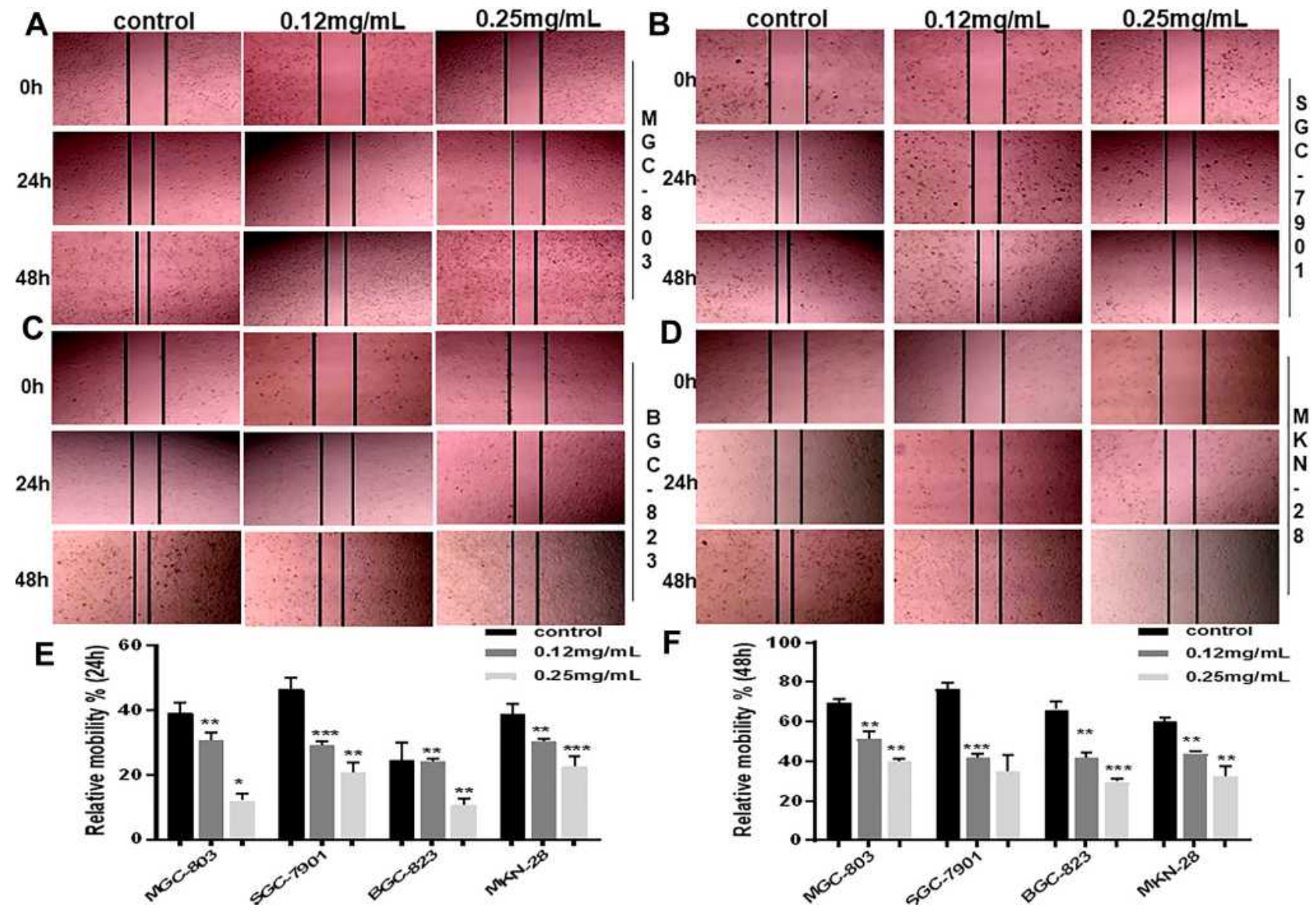

Figure I Continued. 

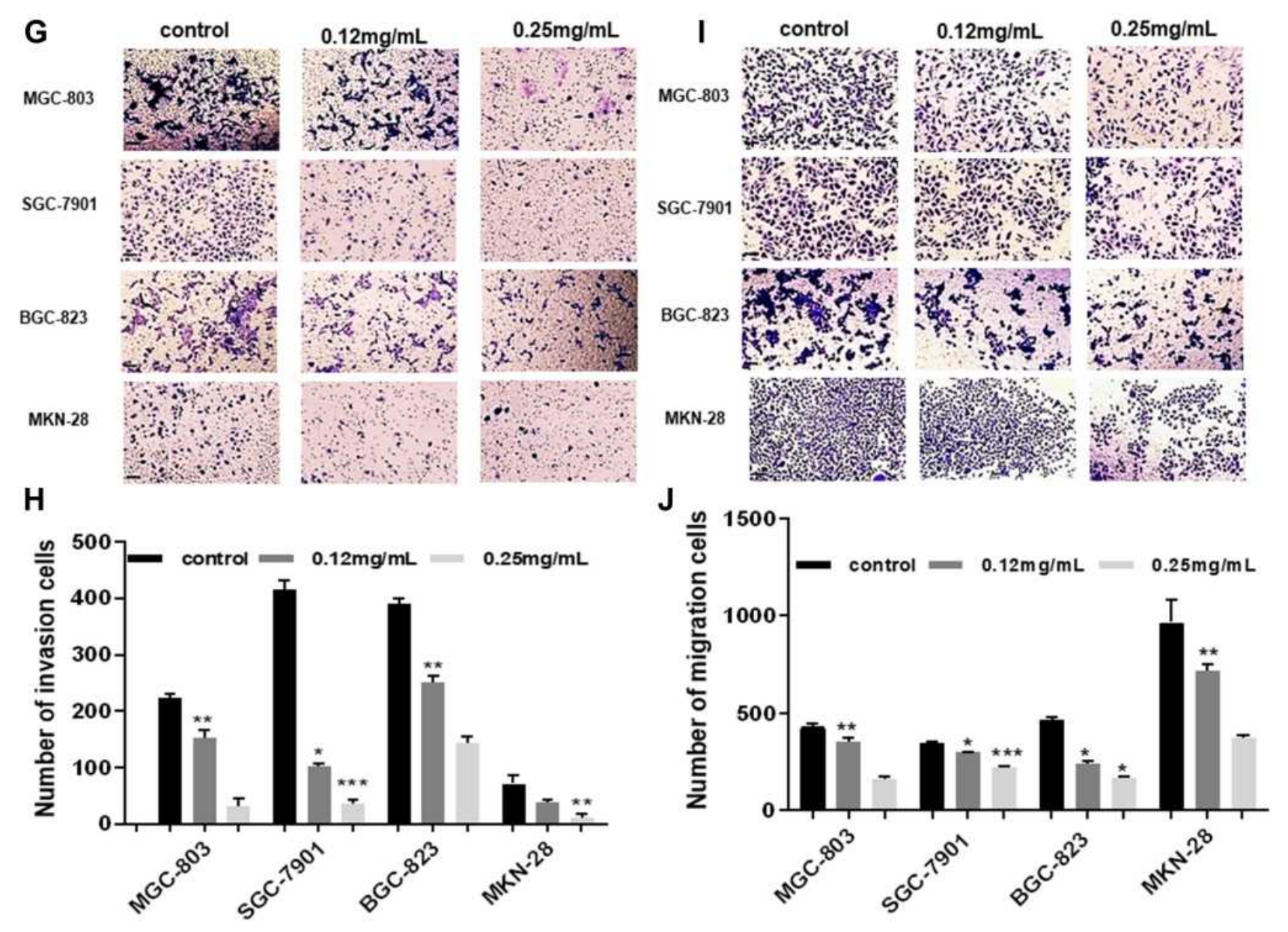

Figure I Continued.

evaluated using the high content screening (HCS). Moreover, the mobility of the selected genes was down regulated by more than two times, which has been reported in previous literature before. The effect of silencing CD13 expression on the mRNA level of the above genes was observed by HCS experiment, and the important gene with the most obvious expression change in the process of controlling GC metastasis were selected.

\section{Western Blot Assays}

Total protein from Ubenimex-treated GC cells was extracted using RIPA lysis buffer containing phenylmethanesulfonyl fluoride (PMSF; Solarbio Biotechnology Co., Shanghai, China) and a protein phosphatase inhibitor (Solarbio) after the cells were washed with ice-cold phosphate-buffered saline (PBS). The protein concentration was measured using the BCA protein assay (Solarbio) after centrifugation at
$10,000 \mathrm{rpm}$ for $8 \mathrm{~min}$. Equal quantities of protein were separated on $10 \%$ SDS polyacrylamide gels and then transferred onto polyvinylidene fluoride (PVDF) membranes (Millipore, Billerica, MA, USA), which were then blocked in 5\% nonfat milk for 2 hours at room temperature. The membranes were then incubated overnight at $4{ }^{\circ} \mathrm{C}$ with the following primary antibodies: anti-ANPEP, anti-phospho-MAPK, anti-NAB1 and anti- $\beta$-actin. The membranes were then washed three times with Tris-buffered saline-Tween (TBST, Solarbio) and incubated with horseradish peroxidaseconjugated secondary antibodies at room temperature for 1.5 hours. The data were analyzed using Bio-Rad Quantity One Software v4.62 (Bio-Rad Laboratories Co., Ltd.). All Western blot analyses were performed at least three times. The grayscale values of the target bands were analyzed using ImageJ software (NIH Image, Bethesda, MD, USA). 

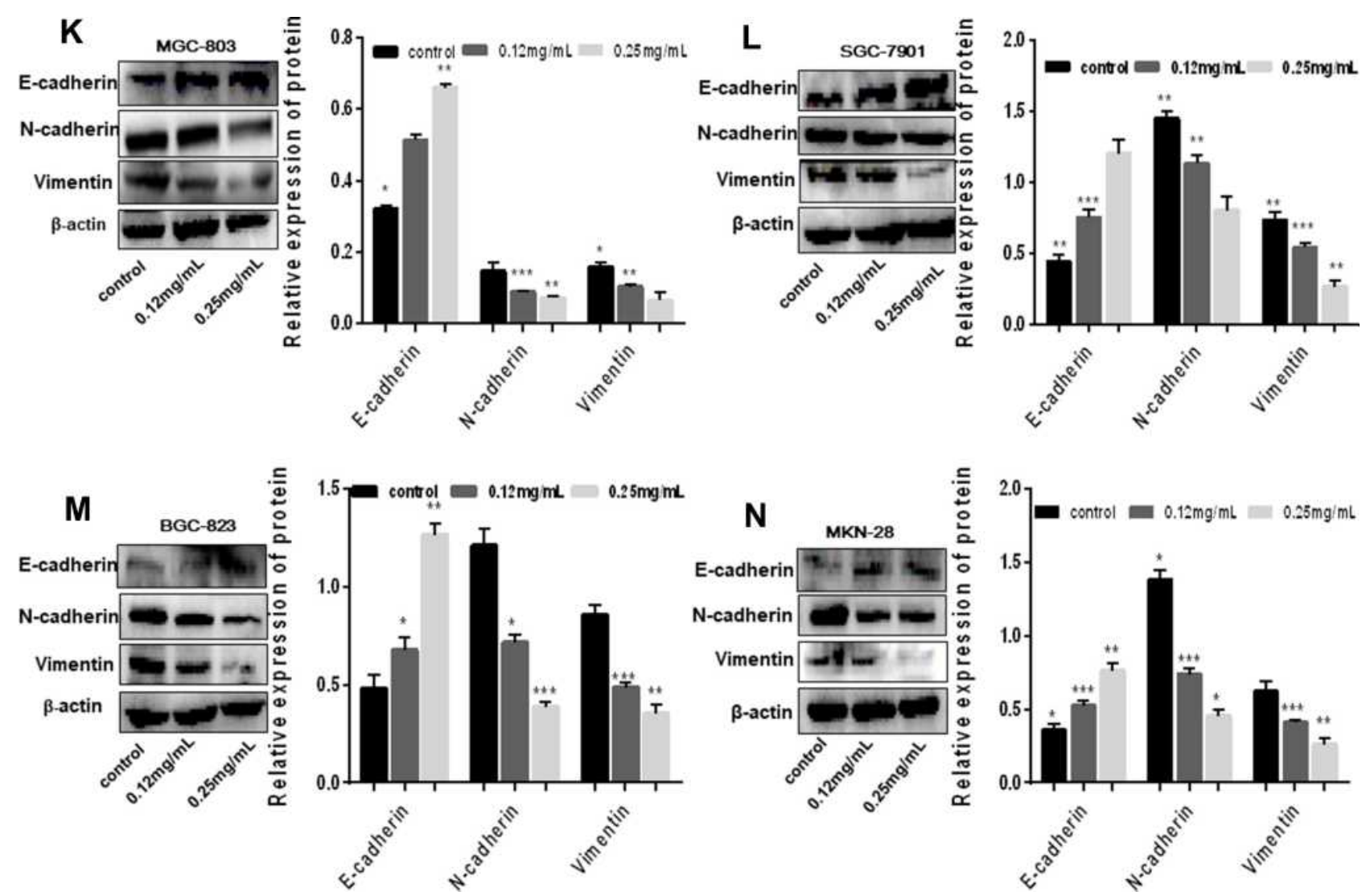

Figure I Ubenimex significantly restrains the migration and invasion potential of GC cells. (A-D) Wound healing assays showing the decreased healing rate of the scratch wound in MGC-803, SGC-790I, BGC-823 and MKN-28 human gastric cells. Representative images are shown. (E and F) The column graph displays a summary of the healing rates. (G and I) Transwell invasion or migration assay with $0.12 \mathrm{mg} / \mathrm{mL}$ or $0.25 \mathrm{mg} / \mathrm{mL}$ of Ubenimex for MGC-803, SGC-790I, BGC-823 and MKN-28 human gastric cells. Photomicrographs of invaded or migrated tumor cells are shown. Bar $=100 \mu \mathrm{m}$. ( $\mathbf{H}$ and $\mathbf{J}$ ) Column graph of the number of invaded or migrated cells. (K-N) Western blot analyses of E-cadherin, N-cadherin, and Vimentin expression in MGC-803, SGC-790I, BGC-823 and MKN-28 human gastric cells. The column graph shows the relative grayscale value of each band compared with that of $\beta$-actin. $* \mathrm{P}<0.05, * * \mathrm{P}<0.0 \mathrm{I}$, and $* * * \mathrm{P}<0.00 \mathrm{I}$.

\section{Transwell Assays}

The migration and invasion capabilities of cultured cells were assessed using a transwell chamber $(8 \mathrm{~mm}, 24-w e l l$ format; Corning) with or without diluted Matrigel (BD Biosciences, San Jose, CA). A 1:8 mixture of Matrigel: DMEM $(40 \mu \mathrm{L})$ was added to the upper chamber at $37^{\circ}$ C for 1 hour. Next, Ubenimex $(0.12 \mathrm{mg} / \mathrm{mL})$ and GC cells $\left(3 \times 10^{5}\right.$ cells $\left./ \mathrm{mL}\right)$, which were serum-starved for 10 hours, were added to the upper chamber. Medium supplemented with $20 \%$ FBS was placed in the bottom chamber. After incubation at $37{ }^{\circ} \mathrm{C}$ with $5 \% \mathrm{CO}_{2}$ for 24 hours, the cells remaining on the upper surface of the membrane were carefully wiped with a cotton swab, and the lower chamber was rinsed with PBS three times. The cells were fixed with $4 \%$ paraformaldehyde for 1 hour and then stained with crystal violet for $40 \mathrm{~min}$. The number of migrated cells was photographed and counted.

\section{Wound Healing Assays}

The wound healing assay was used to detect the migration ability of gastric cells. The cells $\left(5 \times 10^{5}\right.$ cells per well) were added to 6-well plates and incubated overnight until they were $100 \%$ confluent. A scratch was made across the plates using a $10-\mu \mathrm{L}$ pipette. The cells were rinsed twice with PBS, and then complete medium and $0.12 \mathrm{mg} / \mathrm{mL}$ or $0.25 \mathrm{mg} / \mathrm{mL}$ Ubenimex was added to the plates. Next, the cells were incubated at $37^{\circ} \mathrm{C}$ in an atmosphere with $5 \% \mathrm{CO}_{2}$ for a specific time. Subsequently, images were obtained, and the healing area was measured.

\section{Statistical Analysis}

Statistical analysis of the data was conducted using GraphPad Prism 7.0 software (Inc., La Jolla, CA, United States). The data were reported as means \pm standard 
deviation or standard error of the mean, and they were evaluated by one-way analysis of variance. Differences were considered significant at $\mathrm{P}<0.05$. Statistically significant $\mathrm{P}$ values were presented as $* \mathrm{P}<0.05, * * \mathrm{P}<0.01$ and $* * * \mathrm{P}<0.001$. The experiments were performed in triplicate and independently, and the data were presented as three repeats from one independent experiment.

\section{Results}

\section{Ubenimex Significantly Restrains the Migration and Invasion Potential of GC Cells}

Firstly, the wound healing assay was performed to determine whether Ubenimex suppresses GC metastasis. As shown in Figure 1A-F, Ubenimex inhibited the migration abilities of GC cells and the inhibitory effect varied at different concentrations (Figure 1A-F). Additionally, results obtained from the transwell assays confirmed that, compared with the control group, the number of invading and migrating $\mathrm{GC}$ cells treated with Ubenimex was reduced (Figure $1 \mathrm{G}$ and I). Our results demonstrated that Ubenimex weakened the invasion and migration potential of MKN-28, MGC-803, BGC-823 and SGC-7901 cells and the ability of Ubenimex to attenuate GC metastasis increased with increasing drug concentration (Figure $1 \mathrm{H}$ and $\mathrm{J}$ ). Following GC cells treatment with different concentrations of Ubenimex and protein extraction, Western blot assays was used to identify the protein expression of EMT-markers in the various GC cell lines. Consistent with the downregulated $\mathrm{N}$-cadherin expression, the protein expression of Vimentin, determined by Western blot assays, was markedly lower in GC cells treated with Ubenimex than in control group cells. However, E-cadherin expression in GC cells increased gradually with the increase in the Ubenimex concentration (Figure $1 \mathrm{~K}-\mathrm{N}$ ). Collectively, these data

A
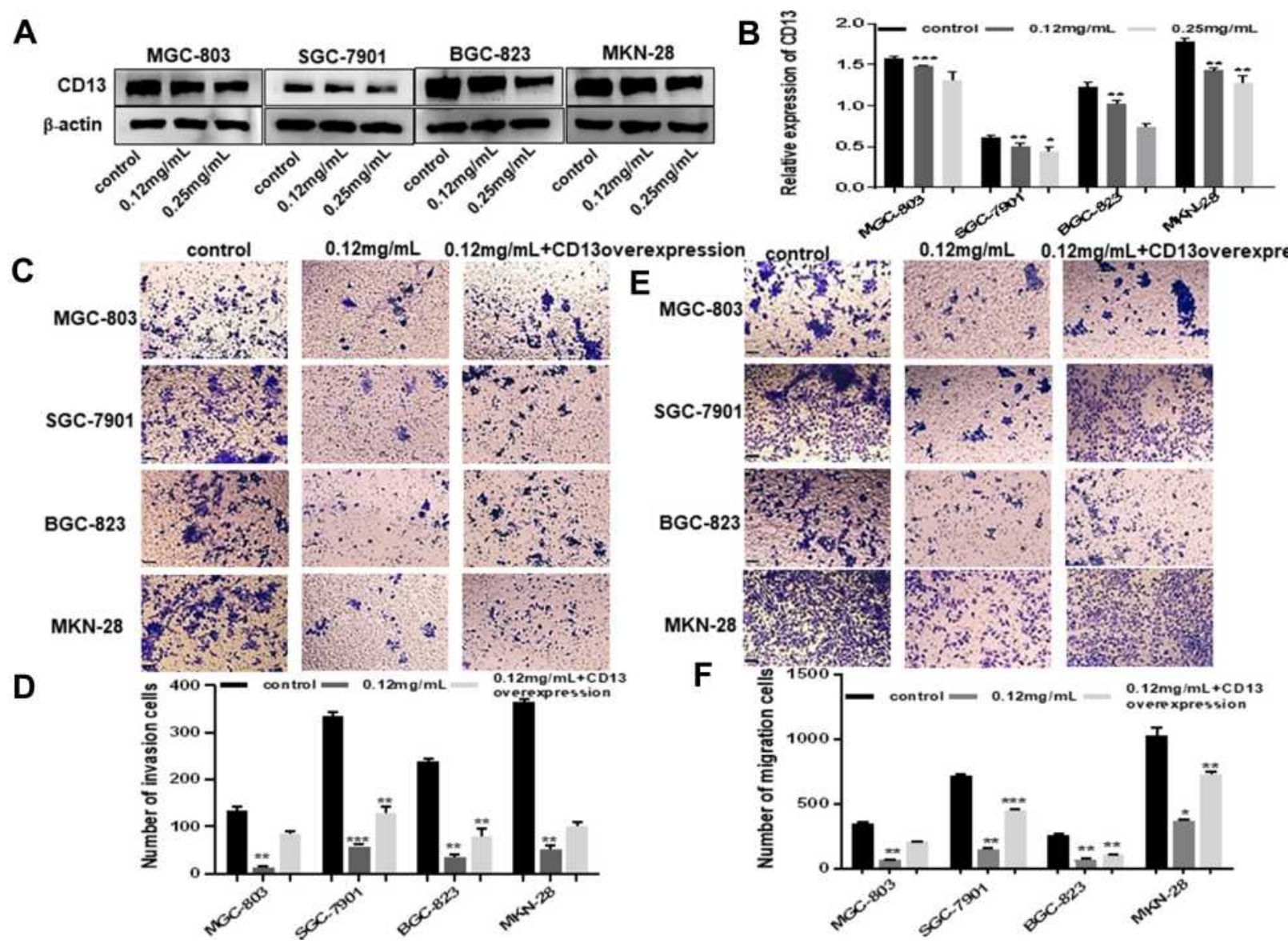

Figure 2 Ubenimex inhibits the invasion and migration of GC cells in which CDI3 reduction is essential. (A) Western blot analyses of CDI3 expression in MGC-803, SGC790I, BGC-823 and MKN-28 human gastric cells. (B) The column graph shows the relative grayscale value of each band compared with that of $\beta$-actin. (C and E) Transwell invasion and migration assays of MGC-803, SGC-790I, BGC-823 and MKN-28 human gastric cells treated with $0.12 \mathrm{mg} / \mathrm{mL}$ or $0.25 \mathrm{mg} / \mathrm{mL}$ of Ubenimex after transfection of $\mathrm{CD} 13$ overexpression plasmids. Bar $=100 \mu \mathrm{m}$. Photomicrographs of invaded or migrated tumor cells. (D and $\mathbf{F}$ ) Column graph of the number of invaded or migrated cells. $* \mathrm{P}<0.05, * * \mathrm{P}<0.01$ and $* * * \mathrm{P}<0.001$. 


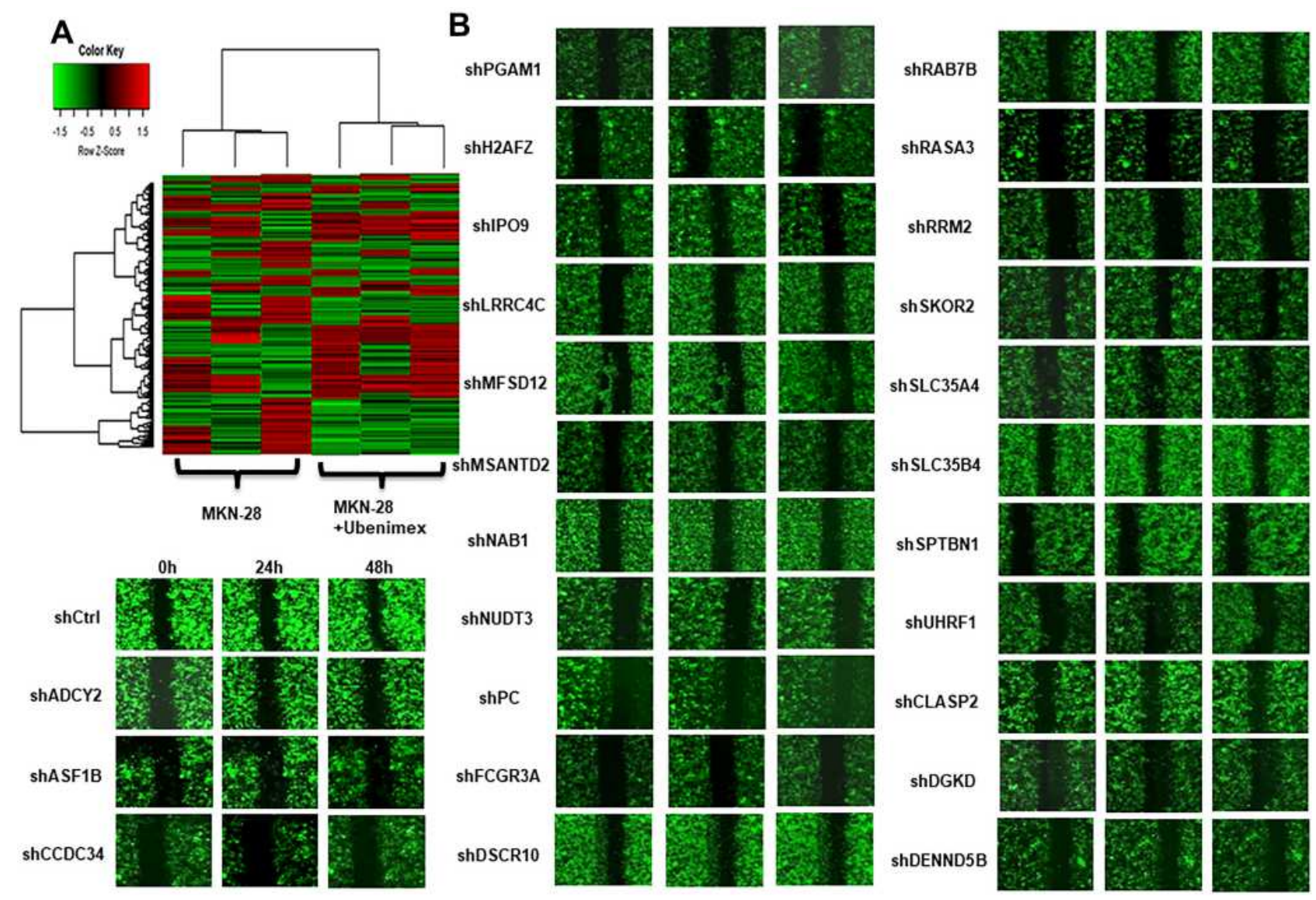

Figure 3 Continued.

indicated that Ubenimex significantly restrains the migration and invasion potential of GC cells.

\section{Ubenimex Inhibits the Invasion and Migration of GC Cells in Which CDI3 Reduction is Essential}

To verify the underlying mechanism in which Ubenimex inhibiting gastric cell migration and invasion ability, we assessed the protein expression of CD13 using Western blot analyses. As expected, the CD13 protein expression exhibited different degrees of reduction after treatment with Ubenimex (Figure 2A and B). Furthermore, the transwell assay was performed to identify whether Ubenimex inhibits the invasion and migration of GC cells by reducing CD13 expression. As shown in Figure 2, the number of invading and migrating cells after transfection of the CD13 overexpression plasmid was less than that of the control group but more than that of the Ubenimex group (Figure 2C-F). Thus, we can infer that the inhibitory ability on GC invasion and migration mediated by Ubenimex was offset after
CD13 overexpression. These results suggested that Ubenimex inhibits the invasion and migration capabilities of GC cells in which $\mathrm{CD} 13$ reduction is indispensable.

\section{Gene Chip Screening and Identification of the Target Gene Associated with Ubenimex-Mediated Metastasis in GC}

To obtain the target gene associated with GC metastasis, we used an Affymetrix Clariom ${ }^{\mathrm{TM}} \mathrm{S}$ gene chip to identify the gene expression profile of MKN-28 cells after Ubenimex treatment. The data showed that Ubenimex downregulated and upregulated multiple genes (Figure 3A). Putative genes that were downregulated by more than two-fold were selected, and these genes may be the strong force triggering tumor metastasis (Figure 3B). These genes were enriched for signaling pathways and selected for high content screening. Evaluation of the changes in the migration rate of MKN-28 cells after silencing the related genes indicated that 25 genes played important roles in Ubenimex-mediated inhibition of GC metastasis. Importantly, NAB1 showed the most significant 


\begin{tabular}{|c|c|c|c|c|c|c|c|c|c|}
\hline Group & $\begin{array}{c}\text { Mobility } \\
\text { Multiple } \\
\text { holes1 }\end{array}$ & $\begin{array}{c}\text { Mobility } \\
\text { Multiple } \\
\text { holes2 }\end{array}$ & $\begin{array}{c}\text { Mobility } \\
\text { AVERAGE }\end{array}$ & $\begin{array}{l}\text { Mobility } \\
\text { STDEV. }\end{array}$ & $\begin{array}{l}\text { Moblity inhibition rate } \\
\text { (shCtrl/test group) } \\
\text { Multiple holes1 }\end{array}$ & $\begin{array}{l}\text { Mobility inhibition rate } \\
\text { (shCtrltest group) } \\
\text { Multiple holes2 }\end{array}$ & $\begin{array}{l}\text { Mobility inhibition rate } \\
\text { (shCtrltest group) } \\
\text { AVERAGE }\end{array}$ & $\begin{array}{l}\text { Mobility in hibition rate } \\
\text { (shCtrltest group) } \\
\text { STDEV. }\end{array}$ & $\begin{array}{l}\text { T-Test Moblity } \\
\text { (shCtrltest group) }\end{array}$ \\
\hline ShUHRFI & $13.28 \%$ & $9.15 \%$ & $11.21 \%$ & 0.03 & 2.59 & 3.76 & 3.17 & 0.83 & 0.067897698 \\
\hline shCtrl & $30.68 \%$ & $38.10 \%$ & $3439 \%$ & 0.05 & 112 & 0.90 & 1.01 & 0.15 & 1 \\
\hline sh SKOR2 & $17.50 \%$ & $14.45 \%$ & $15.98 \%$ & 0.02 & 1.96 & 238 & 2.17 & 0.29 & 0.03850 \\
\hline shDGKD & $17.51 \%$ & $15.84 \%$ & $16.67 \%$ & 0.01 & 1.96 & 217 & 2.07 & 0.15 & 0.01966 \\
\hline shPGAMI & $21.07 \%$ & $18.76 \%$ & $19.91 \%$ & 0.02 & 1.63 & 1.83 & 1.73 & 0.14 & 0,03980 \\
\hline shFCGR3A & $16.61 \%$ & $21.13 \%$ & $18.87 \%$ & 0.03 & 2.07 & 1.63 & 1.85 & 0.31 & 0.07703 \\
\hline shSLC $35 A 4$ & $5323 \%$ & $20.43 \%$ & $36.83 \%$ & 0.23 & 0.65 & 1.68 & 1.16 & 0.73 & 0.80013 \\
\hline ShRASA3 & $11.78 \%$ & $10.65 \%$ & $11.22 \%$ & 0.01 & 2.92 & 3.23 & 3.07 & 0.22 & 0.00830 \\
\hline shCCDC 34 & $16.87 \%$ & $19.00 \%$ & $17.93 \%$ & 0.02 & 2.04 & 1.81 & 1.92 & 0.16 & 0.02867 \\
\hline ShASFIB & $44.45 \%$ & $15.50 \%$ & $29.97 \%$ & 0.20 & 0.77 & 222 & 1.50 & 1.02 & 0.57542 \\
\hline shiP09 & $20.50 \%$ & $19.44 \%$ & $19.97 \%$ & 0.01 & 1.68 & 1.77 & 1.72 & 0.06 & 0.02660 \\
\hline $\operatorname{shNABI}$ & $487 \%$ & $4.64 \%$ & $4.76 \%$ & 0.00 & 7.06 & 7.41 & 7.24 & 0.25 & 0.00110 \\
\hline shDSCRIO & $21.30 \%$ & $36.51 \%$ & $28.90 \%$ & 0.11 & 1.61 & 0.94 & 1.28 & 0.48 & 0.52950 \\
\hline shSPTBNI & $30.84 \%$ & $30.55 \%$ & $30.70 \%$ & 0.00 & 1.12 & 1.13 & 1.12 & 0.01 & 0.42485 \\
\hline shMF SD12 & $28.38 \%$ & $18.13 \%$ & $23.26 \%$ & 0.07 & 1.21 & 1.90 & 1.55 & 0.48 & 0.27017 \\
\hline shNUDT3 & $16.78 \%$ & $26.30 \%$ & $21.54 \%$ & 0.07 & 2.05 & 1.31 & 1.68 & 0.52 & 0.22676 \\
\hline shLRRC 4C & $34.57 \%$ & $43.30 \%$ & $38.93 \%$ & 0.06 & 0.99 & 0.79 & 0.89 & 0.14 & 0.51203 \\
\hline shMSANTD2 & $29.90 \%$ & $30.30 \%$ & $30.10 \%$ & 0.00 & 1.15 & 1.14 & 1.14 & 0.01 & 0.35397 \\
\hline shCLASP2 & $3275 \%$ & $31.45 \%$ & $3210 \%$ & 0.01 & 1.05 & 1.09 & 1.07 & 0.03 & 0.64397 \\
\hline ShDENND5B & $15.60 \%$ & $17.58 \%$ & $16.59 \%$ & 0.01 & 2.20 & 1.96 & 2.08 & 0.18 & 0.02304 \\
\hline $\operatorname{shSLC} 3584$ & $1219 \%$ & $20.67 \%$ & $16.43 \%$ & 0.06 & 2.82 & 1.66 & 2.24 & 0.82 & 0.17183 \\
\hline shRAB7B & $26.44 \%$ & $30.35 \%$ & $28.40 \%$ & 0.03 & 1.30 & 1.13 & 1.22 & 0.12 & 0.27453 \\
\hline shRRM2 & $14.95 \%$ & $11.01 \%$ & $1298 \%$ & 0.03 & 2.30 & 312 & 2.71 & 0.58 & 0.05739 \\
\hline$A D C Y 2$ & $2346 \%$ & $22.99 \%$ & $2323 \%$ & 0.00 & 1.47 & 1.50 & 1.48 & 0.02 & 0.05096 \\
\hline $\operatorname{sh} P C$ & $19.07 \%$ & $19.83 \%$ & $19.45 \%$ & 0.01 & 1.80 & 1.73 & 1.77 & 0.05 & 0,02212 \\
\hline
\end{tabular}

D

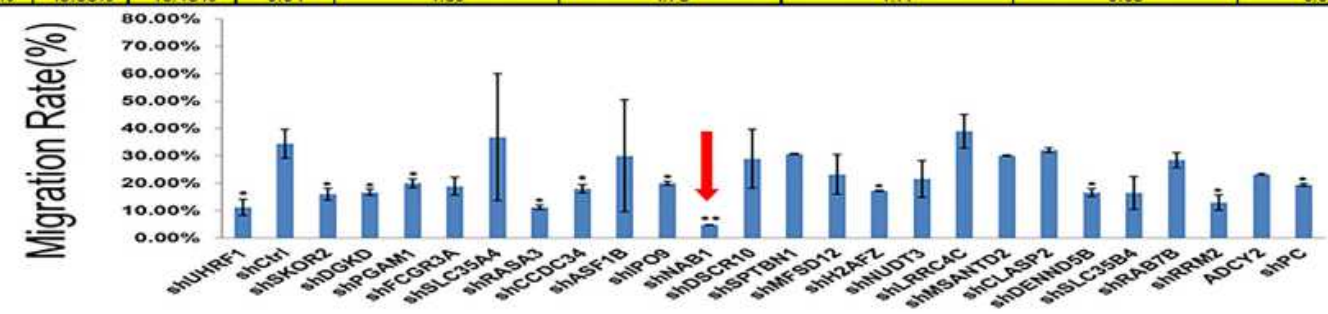

Figure 3 Gene chip screening and identification of the target gene associated with Ubenimex-mediated metastasis in GC. (A) The gene expression spectrum of MKN-28 cells was compared before and after treatment, and the migration rate difference was expressed according to the selection and display criteria of the cluster heat map. (B) Ubenimex reduced the migration rate of GC cells by more than two-fold. The genes associated with the metastasis of GC and other tumors in the literature were selected. The 25 most significantly altered genes were selected. (C) After the 25 genes were silenced, migration assays were performed, and the migration rates are shown in the table. (D) The column graph shows the changes in the migration rates after silencing of the 25 genes. The red arrow indicates that the change in the migration rate was most obvious after $\mathrm{NABI}$ silencing. $* \mathrm{P}<0.05$ and $* * \mathrm{P}<0.0$ I.

downregulation which represented an initiator of evil in promoting GC metastasis (Figure 3C and D). Therefore, these findings suggest that Ubenimex inhibited GC metastasis by targeting $\mathrm{CD} 13$, in which NAB1 downregulation was also essential.

\section{NABI is a Putative Downstream Signal Molecule of CDI3}

To explore relationship between CD13 and NAB1, the protein expression levels after the transfection of the $\mathrm{CD} 13$ or NAB1 overexpression plasmid were measured by Western blot assays. As displayed in Figure $4 \mathrm{~A}-\mathrm{D}$, the expression of NAB1 was increased after CD13 was overexpressed, however, there is not a distinct change in the CD13 expression after NAB1 overexpression. These findings suggest that $\mathrm{CD} 13$ promotes the expression of NAB1 protein in one direction. Furthermore, Western blot assays confirmed that NAB1 expression was downregulated in GC cells with Ubenimex at different concentrations. These findings indicate that NAB1 is a putative target downstream of CD13 (Figure 4E and F). Additionally, Ubenimex inhibits NAB1 expression, which depends on the downregulation of CD13 expression, suggesting that NAB1 is a key molecule by which Ubenimex regulates the expression of CD13 and inhibits the metastasis of GC cells.

\section{Ubenimex Inhibits GC Metastasis by Alleviating the Activation of the CDI3/ NABI/MAPK Signaling Pathway}

A growing body of evidence suggests that NAB1 and MAPK signaling pathways are associated with tumorigenesis, 

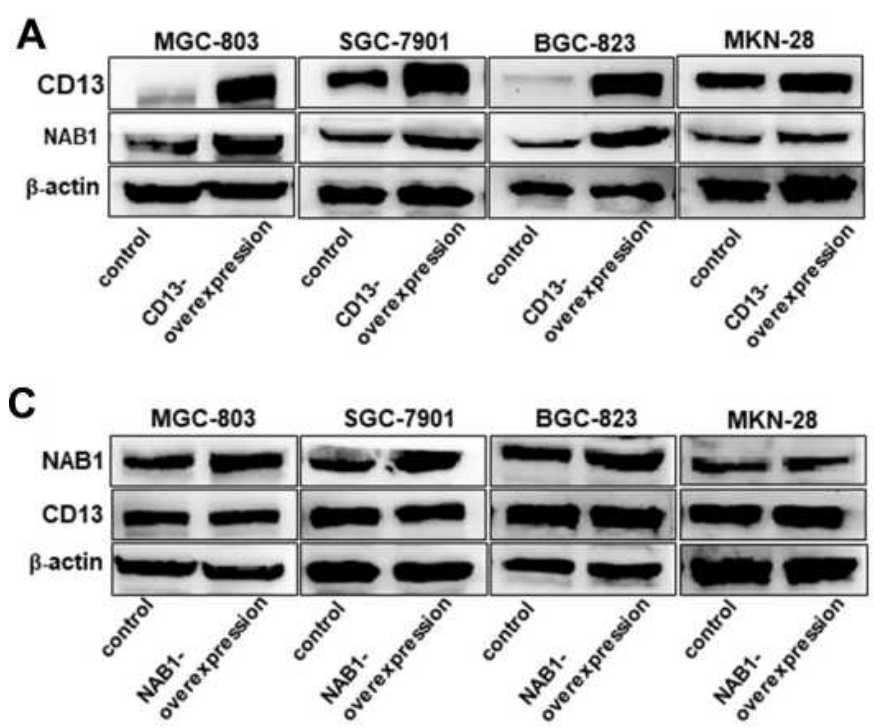

E

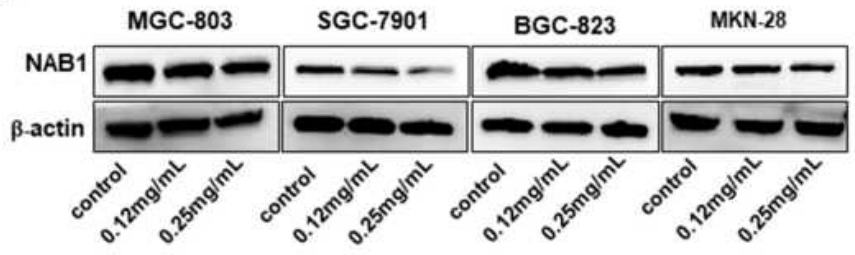

B
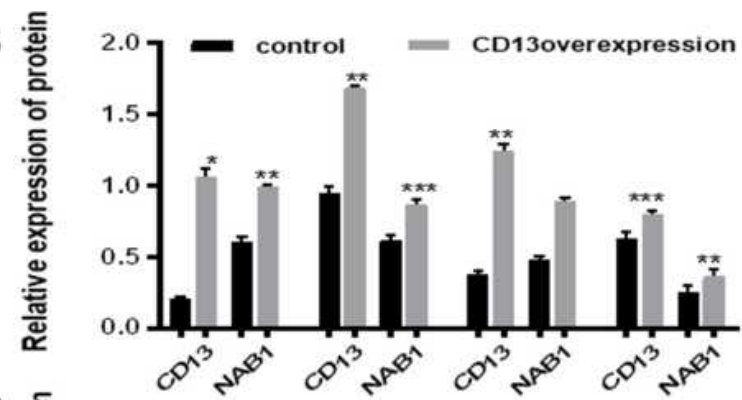

D
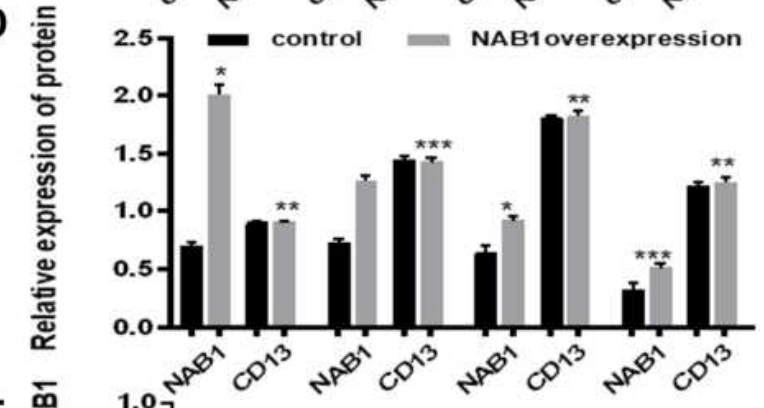

$\mathbf{F}$

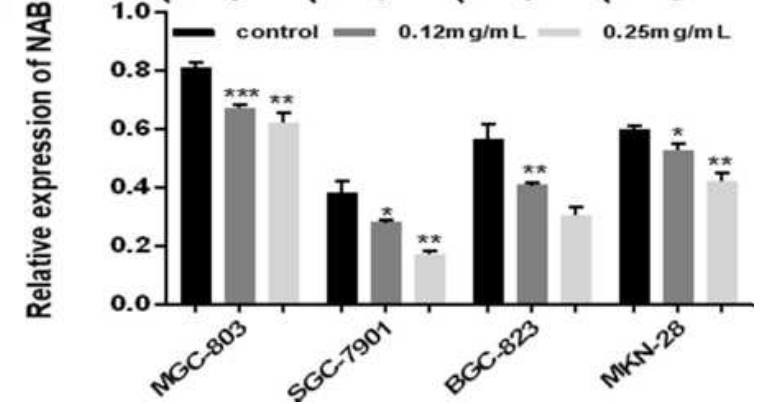

Figure $4 \mathrm{NABI}$ is a putative downstream signal molecule of $C D I 3$. (A) When $C D I 3$ was overexpressed, the level of $N A B I$ was also increased, indicating that $N A B I$ is a target molecule of $C D \mid 3$. (C) When NABI was overexpressed, $C D \mid 3$ expression was not affected, providing further details on the relationship between $N A B I$ and $C D I 3$. (B and D) The column graph shows the relative grayscale value of each band compared with that of $\beta$-actin. (E) Western blot analyses of NABI expression in MGC-803, SGC-790I, BGC-823 and MKN-28 human gastric cells treated with $0.12 \mathrm{mg} / \mathrm{mL}$ or $0.25 \mathrm{~g} / \mathrm{mL}$ Ubenimex. (F) The column graph shows the relative grayscale value of each band compared with that of $\beta$-actin. $* \mathrm{P}<0.05$, $* * \mathrm{P}<0.01$ and $* * * \mathrm{P}<0.001$.

proliferation and metastasis. ${ }^{18}$ To determine whether the inactivation of the MAPK signaling pathway is involved in Ubenimex-mediated inhibition of GC metastasis, the expression of phosphorylated MAPK (p-MAPK) in GC cells after Ubenimex treatment was detected by Western blot assays. The grayscale values of p90RSK, ERK1/2, RPS6, and Rab11 were significantly decreased with increasing Ubenimex concentration, suggesting that the mitigated activation of MAPK signaling pathway was involved in the Ubenimex-mediated inhibition of metastasis (Figure 5A-D). To further investigate how Ubenimex exerts this effect by targeting CD13, thereby affecting the activity of NAB1 and regulating the activation of the MAPK signaling pathway, NAB1 overexpression plasmids were transfected into GC cells. Compared with the Ubenimex-treated group, the protein expression levels of p90RSK, ERK1/2, RPS6 and Rab1 in the NAB1 overexpression plasmid group were significantly higher.
Thus, Ubenimex not only inhibits NAB1 expression by targeting CD13 but also inhibits GC metastasis by regulating the MAPK signaling pathway (Figure 5E-H). Additionally, in the transwell migration and invasion assays, high NAB1 expression significantly increased the ability of GC cells for migration and invasion compared with GC cells treated with Ubenimex. (Figure 5I-L). These results indicated that Ubenimex inhibited the proliferation, migration, and invasion of GC cells via the activation of the CD13/NAB1/ MAPK signaling pathway.

\section{Discussion}

As acknowledged, Ubenimex plays a role in enhancing immune function, mainly in the response to chemotherapy and adjuvant radiotherapy and in age-related immune deficiency. ${ }^{19}$ Ubenimex can be used with chemotherapy, radiotherapy or both in treating leukemia, multiple myeloma, 

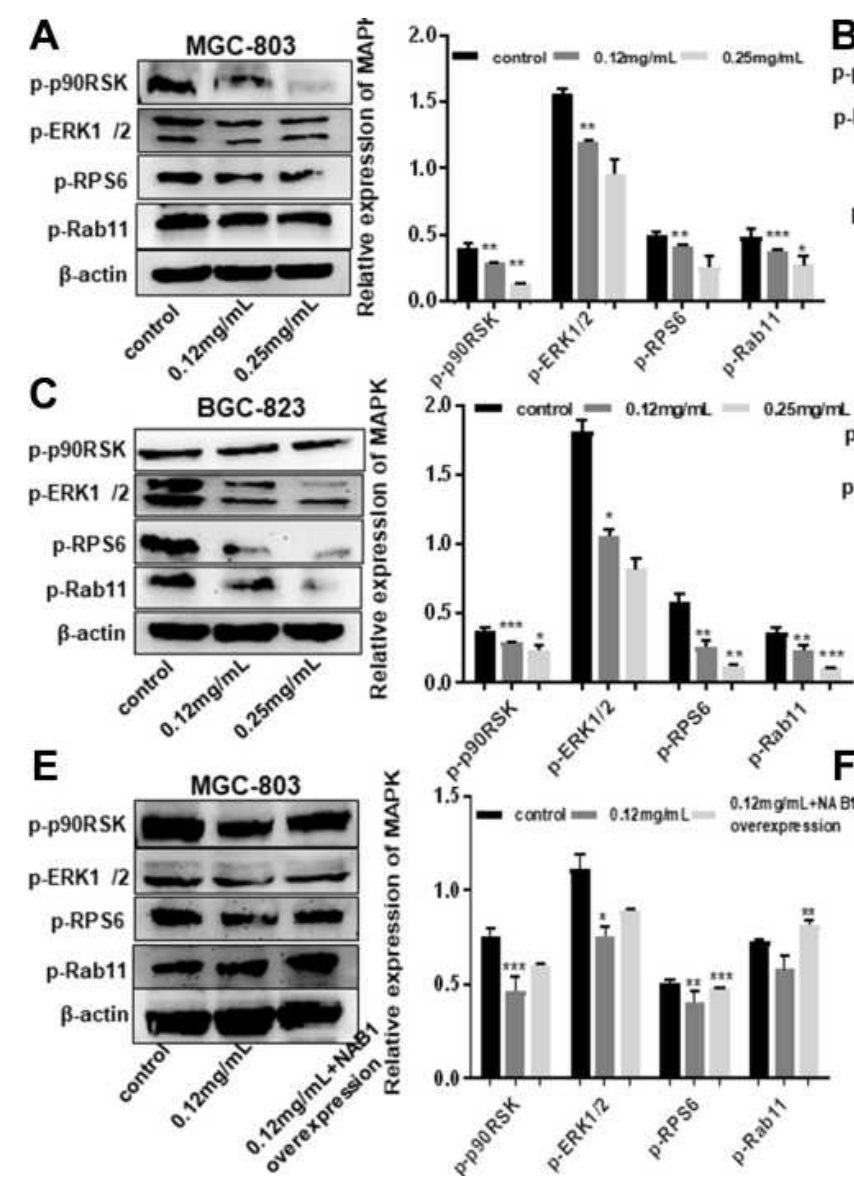

Figure 5 Continued.

bone marrow syndrome, hematopoietic stem cell transplantation and solid tumors. ${ }^{20}$ However, few studies have reported that it has functions in inhibiting gastric metastasis. CD13 was first characterized as a surface marker for hematopoietic cells of myeloid origin, ${ }^{21,22}$ and it is expressed in different cell types, such as epithelial cells, nerve cells, fibroblasts and endothelial cells. ${ }^{23}$ Notably, CD13 is overexpressed in acute myeloid leukemia cells and multiple solid tumors, including lung cancer, colon cancer and ovarian cancer, inducing tumor proliferation and suppressing apoptosis, and also enhancing cell aggression and vascularization. ${ }^{24}$ An increasing number of studies have demonstrated that CD13 inhibitors improve the efficacy of chemotherapy. However, no study has shown the effect of Ubenimex in restraining GC metastasis via targeting CD13. Here, we demonstrated that Ubenimex influences the migration and invasion capacity of GC cells to inhibit GC metastasis. Compared with the control group, Ubenimex reduced the CD13 protein expression and GC cell migration after the transfection of CD13 overexpression plasmids.

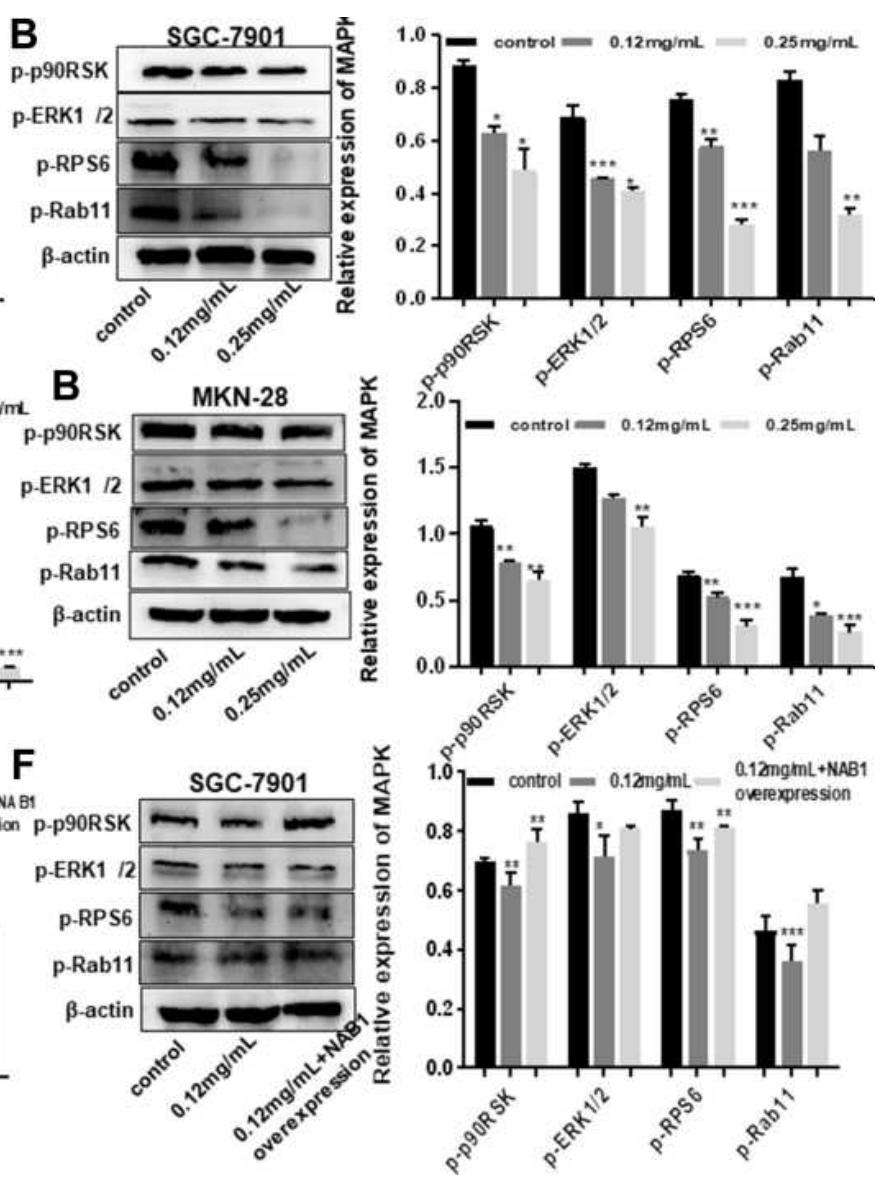

In this study, gene chip technology and high content screening were used to screen out the gene associated with Ubenimex-mediated inhibition of GC metastasis, and NAB1 was identified as a putative targeted gene. Nerve growth factor (NGF1)-A-binding protein (NAB1), also known as zif268, Egr1 and Krox-24, is a zinc finger transcription factor. ${ }^{25}$ NAB1 is associated with the transcription of the Egr family transcription factors Egr1 (Krox-24), Egr2 (Krox-20) and Egr3 (PILOT). ${ }^{9}$ NAB1 promotes the development of the posterior brain by regulating spinal nerve sheath-related genes in Schwann cells. One study has indicated that NAB1 is a transcription inhibition factor that inhibits myocardial fat deposition and its expression inhibits the progression of pathological obesity but allows the growth and development of muscle cells. ${ }^{26}$ NAB1 is encoded in response to various extracellular stimulants, ${ }^{27}$ including cell proliferation, macrophage differentiation, synaptic activation and long-range enhancement. In the present study, we explored the mechanism of NAB1 as an important molecule in tumors, and we 


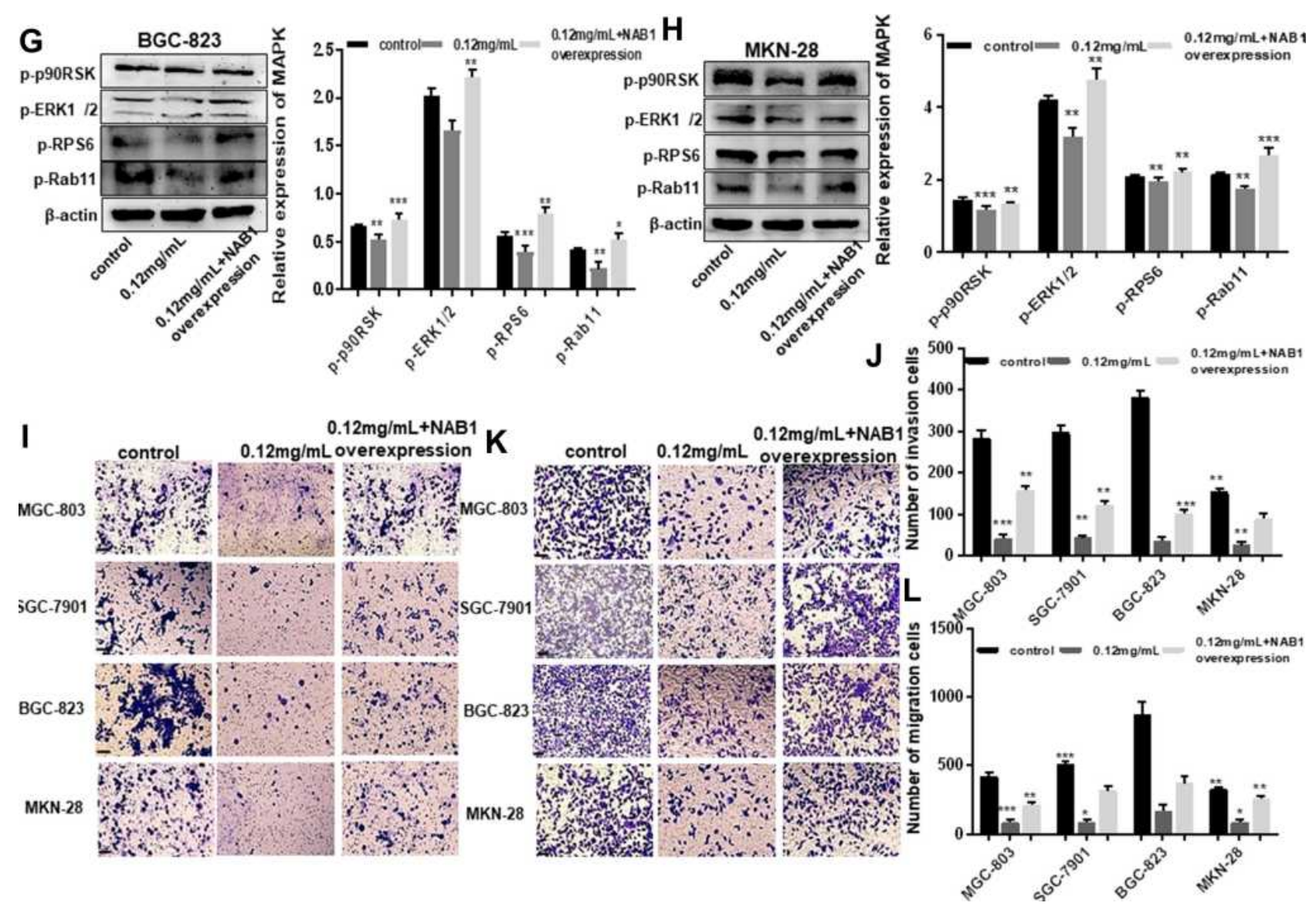

Figure 5 Ubenimex inhibits GC metastasis by alleviating the activation of the CDI3/NABI/MAPK signaling pathway. (A-D) Western blot analyses of MAPK expression in MGC-803, SGC-790 I, BGC-823 and MKN-28 human gastric cells treated with $0.12 \mathrm{mg} / \mathrm{mL}$ or $0.25 \mathrm{mg} / \mathrm{mL}$ of Ubenimex. The column graph shows the relative grayscale value of each band compared with $\beta$-actin. (E-H) GC cells were treated with $0.12 \mathrm{mg} / \mathrm{mL}$ Ubenimex and then either left non-transfected or transfected with the NABI overexpression plasmid. The protein expression levels were then compared between the transfected and non-transfected cells. The column graph shows the relative grayscale value of each band compared with $\beta$-actin. ( $\mathbf{I}$ and $\mathbf{K}$ ) The transwell invasion or migration assay with $0.12 \mathrm{mg} / \mathrm{mL}$ of Ubenimex or $0.12 \mathrm{mg} / \mathrm{mL}$ of Ubenimex added NABI overexpression plasmids for MGC-803, SGC-790I, BGC-823 and MKN-28 human gastric cells. Photomicrographs of invaded or migrated tumor cells are shown. Bar $=100 \mu \mathrm{m}$. (J and $\mathbf{L})$ Column graph of the number of invaded or migrated cells. ${ }^{*} \mathrm{P}<0.05,{ }^{*} \mathrm{P}<0.0 \mathrm{I}$ and $* * * \mathrm{P}<0.00 \mathrm{I}$; MAPK: mitogen-activated protein kinase.

investigated its related signaling pathways. Our study found that Ubenimex, which is widely used in clinics for immunosuppression, regulates NAB1 by targeting CD13, thereby affecting GC metastasis. Few reports on NAB1 and GC metastasis exist in the literature. Our study revealed a novel research area involving NAB1 in GC.

MAPKs belong to the serine-threonine kinase family, which is widely expressed in various cells as the following three main subfamilies: extracellular signal-regulated kinases (ERK MAPK, Ras, Raf1, MEK and ERK), c-Jun N-terminal kinase or stress-activated protein kinases (JNK or SAPKs), and MAPK14. ${ }^{28,29}$ An increasing number of studies have demonstrated that MAPK signaling pathways, including JNK, ERK and p38 kinases, ${ }^{30,31}$ play pivotal roles in the proliferation, invasion and migration of cancer cells. Some studies have shown that ERK is a core kinase of the MAPK family, and ERK was crucial in promoting cell proliferation, apoptosis, differentiation and growth. ${ }^{32,33}$ ERK is activated by various oncogenes and extracellular stimuli. Recent studies have also shown that the ERK and MAPK pathways are crucial for the proliferation and migration of GC cells. ${ }^{34}$ The effects of Helicobacter pylori infection, heparanase (HPA) and MAPK protein expression in GC have been analyzed by studying the associations between the clinical pathological characteristics of GC and the above factors. ${ }^{35}$ Both positive HPA expression and positive MAPK expression are associated with the depth of invasion. ${ }^{36}$ Many studies have investigated the involvement of p-38 and JNK in the MAPK signaling pathway, supporting that the pathway explored in the present study is related to MAPK. ${ }^{37-39}$ However, in our study, the alterations of four molecules (p90RSK, ERK1/2, RPS6 and Rab11) demonstrated that 
Ubenimex regulates the MAPK signaling pathway. This study suggests that Ubenimex inhibits GC metastasis by targeting CD13 and further regulating the MAPK pathway. The experimental results provided new ideas and potential new applications for Ubenimex in the future.

In summary, the present study demonstrated that Ubenimex suppresses the growth of the MGC-803, SGC7901, BGC-823 and MKN-28 human GC cell lines in vitro. Ubenimex inhibits the invasion, migration and metastasis of human GC cells by targeting CD13 and activating the MAPK signaling pathway. Additionally, Ubenimex regulates the activity of $\mathrm{NAB} 1$, revealing the correlation among CD13, NAB1 and MAPK signaling pathway proteins. Therefore, our study supports the potential therapeutic value of Ubenimex in inhibiting the metastasis of MGC803, SGC-7901, BGC-823 and MKN-28 human GC cells, indicating a new application of Ubenimex, thereby providing a new foundation for further scientific research.

\section{Abbreviations}

GC, gastric cancer; Ube, Ubenimex; APN, aminopeptidase $\mathrm{N}$; NAB1, NGFI-A binding protein 1; JNK, Jun N-terminal kinase; ERK, extracellular regulated protein kinases; MAPK, mitogen-activated protein kinase.

\section{Data Sharing Statement}

The data used to support the findings of this study are available from the corresponding author upon request.

\section{Acknowledgments}

This work was supported by the Natural Science Foundation of Shandong Province, China (ZR2017MH045). We all thank the American Journal experts for language editing.

\section{Author Contributions}

All authors made a significant contribution to the work reported, whether that is in the conception, study design, execution, acquisition of data, analysis and interpretation, or in all these areas; took part in drafting, revising or critically reviewing the article; gave final approval of the version to be published; have agreed on the journal to which the article has been submitted; and agree to be accountable for all aspects of the work.

\section{Disclosure}

The authors declared no potential conflicts of interest for this work.

\section{References}

1. Fock KM. Review article: the epidemiology and prevention of gastric cancer. Aliment Pharmacol Ther. 2014;40(3):250-260. doi:10.1111/ apt. 12814

2. Bianca B, Meyer TF. The human gastric pathogen helicobacter pylori and its association with gastric cancer and ulcer disease. Ulcers. 2011;2011:1-23. doi:10.1155/2011/340157

3. Khushalani NI. Cancer of the esophagus and stomach. Practitioner. 2008;83(6):712-722. doi:10.1016/S0025-6196(11)60900-2

4. Ruan T, Liu W, Tao K, Wu CA. Review of research progress in multidrug-resistance mechanisms in gastric cancer. Onco Targets Ther. 2020;13:1797-1807. doi:10.2147/OTT.S239336

5. Jun SY, Park JK. Metachronous ovarian metastases following resection of the primary gastric cancer. $J$ Gastric Cancer. 2011;11 (1):31-37. doi:10.5230/jgc.2011.11.1.31

6. Guzman-Rojas L, Rangel R, Salameh A, et al. Cooperative effects of aminopeptidase $\mathrm{N}$ (CD13) expressed by nonmalignant and cancer cells within the tumor microenvironment. Proc Natl Acad Sci U S A. 2012;109(5):1637-1642. doi:10.1073/pnas.1120790109

7. Highley MS, Parnis FX, Trotter GA, et al. Combination chemotherapy with epirubicin, cisplatin and 5-fluorouracil for the palliation of advanced gastric and oesophageal adenocarcinoma. $\mathrm{Br} J$ Surg. 1994;81(12):1763-1765. doi:10.1002/bjs. 1800811218

8. Yamazaki T, Sugiyama K, Ichihara K. Effect of ubenimex on the immune system of patients with hematological malignancies. Biomed Pharmacother. $\quad$ 1991;45(2-3):105-112. doi:10.1016/0753-3322(91) 90129-h

9. Swirnoff AH, Apel ED, Svaren J, et al. Nab1, a corepressor of NGFI-A (Egr-1), contains an active transcriptional repression domain. Mol Cell Biol. 1998;18(1):512-524. doi:10.1128/ mcb.18.1.512

10. LaVallee J, Grant T, D'Angelo-Early S, et al. Refining the nuclear localization signal within the Egr transcriptional coregulator NAB2. FEBS Lett. 2019;593(1):107-118. doi:10.1002/1873-3468.13288

11. Zhao L, Yuan Y, Li P, et al. miR-221-3p inhibits schwann cell myelination. Neuroscience. 2018;379:239-245. doi:10.1016/j. neuroscience.2018.03.019

12. Tikiyani V, Li L, Sharma P, Liu H, Hu Z, Babu K. Wnt secretion is regulated by the tetraspan protein HIC-1 through its interaction with neurabin/NAB-1. Cell Rep. 2018;25(7):1856-1871.e6. doi:10.1016/j. celrep.2018.10.053

13. Qiu FH, Devchand PR, Wada K, Serhan CN. Aspirin-triggered lipoxin A4 and lipoxin A4 up-regulate transcriptional corepressor NAB1 in human neutrophils. FASEB J. 2001;15(14):2736-2738. doi:10.1096/fj.01-0576fje

14. Xiang Z, Li J, Song S, et al. A positive feedback between IDO1 metabolite and COL12A1 via MAPK pathway to promote gastric cancer metastasis. J Exp Clin Cancer Res. 2019;38(1):314. doi:10.1186/s13046-019-1318-5

15. Liu H, Zhao YR, Chen B, Ge Z, Huang JS. High expression of SMARCE1 predicts poor prognosis and promotes cell growth and metastasis in gastric cancer. Cancer Manag Res. 2019;11:3493-3509. doi:10.2147/CMAR.S195137

16. Wong D, Kandagatla P, Korz W, Chinni SR. Targeting CXCR4 with CTCE-9908 inhibits prostate tumor metastasis. BMC Urol. 2014;14 (1):12. doi:10.1186/1471-2490-14-12

17. Kobayashi H, Suzuki M, Kanayama N, Terao T. Genetic down-regulation of phosphoinositide 3-kinase by bikunin correlates with suppression of invasion and metastasis in human ovarian cancer HRA cells. $J$ Biol Chem. 2004;279(8):6371-6379. doi:10.1074/jbc. M305749200

18. Kosla J, Dvorakova M, Dvorak M, Cermak V. Effective myofibroblast dedifferentiation by concomitant inhibition of TGF- $\beta$ signaling and perturbation of MAPK signaling. Eur J Cell Biol. 2013;92 (12):363-373. doi:10.1016/j.ejcb.2013.10.013 
19. Sakuraya M, Tamura J, Itoh K, Kubota K, Naruse T. Aminopeptidase inhibitor ubenimex inhibits the growth of leukaemic cell lines and myeloma cells through its cytotoxicity. J Int Med Res. 2000;28 (5):214-221. doi:10.1177/147323000002800503

20. Urabe A, Mutoh Y, Mizoguchi H, Takaku F, Ogawa N. Ubenimex in the treatment of acute nonlymphocytic leukemia in adults. Ann Hematol. 1993;67(2):63-66. doi:10.1007/BF01788128

21. Riemann D, Kehlen A, Langner J. CD13-not just a marker in leukemia typing. Immunol Today. 1999;20(2):83-88. doi:10.1016/s01675699(98)01398-x

22. Haraguchi N, Ishii H, Mimori K, et al. CD13 is a therapeutic target in human liver cancer stem cells. J Clin Invest. 2010;120(9):3326-3339. doi:10.1172/JCI42550

23. Saiki I, Fujii H, Yoneda J, et al. Role of aminopeptidase N (CD13) in tumor-cell invasion and extracellular matrix degradation. Int $J$ Cancer. 1993;54(1):137-143. doi:10.1002/ijc.2910540122

24. Pang L, Zhang N, Xia Y, Wang D, Wang G, Meng X. Serum APN/ CD13 as a novel diagnostic and prognostic biomarker of pancreatic cancer. Oncotarget. 2016;7(47):77854-77864. doi:10.18632/ oncotarget. 12835

25. Russo MW, Sevetson BR, Milbrandt J. Identification of NAB1, a repressor of NGFI-A- and Krox20-mediated transcription. Proc Natl Acad Sci U S A. 1995;92(15):6873-6877. doi:10.1073/ pnas.92.15.6873

26. Sagrillo CA, Selmanoff M. Effects of prolactin on expression of the mRNAs encoding the immediate early genes zif/268 (NGF1-A), nur/ 77 (NGF1-B), c-fos and c-jun in the hypothalamus. Brain Res Mol Brain Res. 1998;61(1-2):62-68. doi:10.1016/s0169-328x(98)00198-3

27. Morinobu S, Strausbaugh H, Terwilliger R, Duman RS. Regulation of c-Fos and NGF1-A by antidepressant treatments. Synapse. 1997;25 (4):313-320. doi:10.1002/(SICI)1098-2396(199704)25:4<313::AIDSYN1>3.0.CO;2-D

28. Fang JY, Richardson BC. The MAPK signalling pathways and colorectal cancer. Lancet Oncol. 2005;6(5):322-327. doi:10.1016/S14702045(05)70168-6

29. Kyriakis JM, Avruch J. Mammalian MAPK signal transduction pathways activated by stress and inflammation: a 10-year update. Physiol Rev. 2012;92(2):689-737. doi:10.1152/physrev.00028.2011
30. Hsieh YY, Shen CH, Huang WS, et al. Resistin-induced stromal cellderived factor-1 expression through toll-like receptor 4 and activation of p38 MAPK/NFкB signaling pathway in gastric cancer cells. $J$ Biomed Sci. 2014;21(1):59. doi:10.1186/1423-0127-21-59

31. Deak M, Clifton AD, Lucocq LM, Alessi DR. Mitogen- and stress-activated protein kinase-1 (MSK1) is directly activated by MAPK and SAPK2/p38, and may mediate activation of CREB. EMBO J. 1998;17(15):4426-4441. doi:10.1093/emboj/17.15.4426

32. Wei L, Li Y, Suo Z. TSPAN8 promotes gastric cancer growth and metastasis via ERK MAPK pathway. Int J Clin Exp Med. 2015;8 (6):8599-8607.

33. Seger R, Krebs EG. The MAPK signaling cascade. FASEB J. 1995;9 (9):726-735. doi:10.1096/fasebj.9.9.7601337

34. Roux PP, Blenis J. ERK and p38 MAPK-activated protein kinases: a family of protein kinases with diverse biological functions. Microbiol Mol Biol Rev. 2004;68(2):320-344. doi:10.1128/ MMBR.68.2.320-344.2004

35. Liu LP, Sheng XP, Shuai TK, Zhao YX, Li B, Li YM. Helicobacter pylori promotes invasion and metastasis of gastric cancer by enhancing heparanase expression. World J Gastroenterol. 2018;24 (40):4565-4577. doi:10.3748/wjg.v24.i40.4565

36. Bonni A, Brunet A, West AE, Datta SR, Takasu MA, Greenberg ME. Cell survival promoted by the Ras-MAPK signaling pathway by transcription-dependent and independent mechanisms. Science. 1999;286(5443):1358-1362. doi:10.1126/science.286.5443.1358

37. Xing J, Ginty DD, Greenberg ME. Coupling of the RAS-MAPK pathway to gene activation by RSK2, a growth factor-regulated CREB kinase. Science. 1996;273(5277):959-963. doi:10.1126/ science.273.5277.959

38. Carracedo A, Ma L, Teruya-Feldstein J, et al. Inhibition of mTORC1 leads to MAPK pathway activation through a PI3K-dependent feedback loop in human cancer. J Clin Invest. 2008;118(9):3065-3074. doi:10.1172/JCI34739

39. Song YX, Yue ZY, Wang ZN, et al. MicroRNA-148b is frequently down-regulated in gastric cancer and acts as a tumor suppressor by inhibiting cell proliferation. Mol Cancer. 2011;10(1):1. doi:10.1186/ 1476-4598-10-

\section{Publish your work in this journal}

Cancer Management and Research is an international, peer-reviewed open access journal focusing on cancer research and the optimal use of preventative and integrated treatment interventions to achieve improved outcomes, enhanced survival and quality of life for the cancer patient.
The manuscript management system is completely online and includes a very quick and fair peer-review system, which is all easy to use. Visit http://www.dovepress.com/testimonials.php to read real quotes from published authors. 